\title{
Pelatihan Pembuatan Ecobrick kepada Anak-Anak Siswa SD Kanisisus Kembaran, Bantul, Yogyakarta
}

\author{
Istiana Adianti ${ }^{1}$, Nurina V.Ayuningtyas ${ }^{2}$ \\ ${ }^{1}$ Program Studi Arsitektur, Fakultas Teknik, Universitas Widya Mataram Yogyakarta, Email : \\ tinaadianti@gmail.com \\ 2 Program Studi Arsitektur, Fakultas Teknik, Universitas Widya Mataram Yogyakarta, Email : \\ nurina.vidya@gmail.com
}

\begin{abstract}
Indonesia has a big problem in managing waste. The use of plastic bottles is increasingly prevalent in the community. Behind this is the fact that the use of plastic bottles has a very bad impact on environmental residues because the process of decomposing plastic bottles can take 450 to 1,000 years. In the field of architecture, how to preserve the earth can be done by designing environmentally friendly buildings. One of the recycled materials that can be used is eco-brick. Various kinds of rubbish such as plastic bottles, sachets / plastic packaging are put together with the appropriate stages and processes so that the quality is fulfilled to be used as design or building materials. With the application of eco-brick, it is expected to reduce the amount of plastic waste and beverage bottles to become more useful and educate the public about the dangers of plastic waste and provide training related to the use of plastic waste so that it can be used again. With the introduction of innovations and training in making eco-bricks, it is hoped that students or children will begin to realize the worsening environmental conditions, so that students are able to act to save the earth from increasing amounts of plastic waste. The workshop materials and process received a good response from the participants. With the results obtained from this workshop, it is expected to be able to educate young people to care about the condition of the earth and the environment.
\end{abstract}

Keywords: Workshop Ecobrick, Ecobrick Plastic, Bottle, Earth

\begin{abstract}
Abstrak
Indonesia menghadapi persoalan besar dalam mengelola sampah. Penggunaan botol plastik semakin marak di masyarakat. Dibalik itu terdapat fakta bahwa penggunaan botol plastik memiliki dampak yang sangat buruk terhadap residu lingkungan karena proses penguraian botol plastik bisa memakan waktu 450 sampai 1.000 tahun. Pada bidang arsitektur, cara menjaga bumi dapat dilakukan dengan mendesain bangunan yang ramah lingkungan. Salah satu bahan material daur ulang yang dapat digunakan adalah eco-brick. Berbagai macam sampah seperti botol plastik, sachet/ plastik kemasan dijadikan satu dengan tahapan dan proses yang sesuai sehingga terpenuhi kualitasnya untuk dijadikan bahan rancangan ataupun bangunan. Dengan pengaplikasian eco-brick ini diharapkan mampu mengurangi besaran jumlah sampah plastik dan botol minuman untuk kemudian dapat menjadi hal yang lebih bermanfaat serta mengedukasi masyarakat tentang bahaya sampah plastik dan memberikan pelatihan terkait pemanfaatan sampah plastik agar dapat berguna kembali. Dengan adanya pengenalan inovasi dan pelatihan pembuatan eco-brick ini diharapkan siswasiswa atau anak-anak mulai sadar tentang kondisi lingkungan yang kian memburuk, sehingga para siswa mampu bertindak untuk menyelamatkan bumi dari jumlah sampah plastik yang semakin banyak. Materi dan proses pelaksanaan workshop mendapat tanggapan yang baik dari para peserta. Dengan hasil yang diperoleh dari workshop
\end{abstract}


ini harapannya mampu mendidik generasi muda supaya peduli terhadap kondisi bumi dan lingkungan.

Kata Kunci: Pelatihan Ecobrick, Ecobrick, Plastik, Botol, Bumi

\section{PENDAHULUAN}

Saat ini, Indonesia menghadapi persoalan besar dalam mengelola sampah (Hary, 1999). Volume sampah yang dihasilkan semakin banyak, dan sebagian besar terdiri dari sampah plastik yang tidak mudah terurai. Indonesia membuang limbah plastik sebanyak 3,2 juta ton, dan menempatkan indonesia diurutan kedua sebagai negara penyumbang sampah plastik ke laut setelah Cina (Bambang, 2006). Dari sekian banyak limbah plastik yang ada, botol plastik ditengarai memiliki dampatk sangat buruk terhadap residu lingkungan (Taufik, 2018) Salah satu solusi untuk mengatasinya adalah dengan melakukan upaya memanfaatkan ulang sampah plastik sehingga diharapkan volume sampah plastik bisa berkurang.

Hal tersebut terjadi karena proses penguraian botol plastik memakan waktu 450-1.000 tahun, dan oleh karenanya sampah botol plastik dapat menjadi limbah. Sehingga sampah botol plastik akan menjadi limbah yang sangat berbahaya. Atas dasar hal tersebut maka saat ini sudah banyak negara yang mengurangi produksi botol plastik untuk mengurangi dampak lingkungan yang terjadi. Selain itu berbagai upaya pemanfanfaatan sampah botol plastik untuk didaur ulang juga terus digaungkan di masyarakat.

Pada bidang arsitektur, cara menjaga bumi dapat dilakukan dengan mendesain bangunan yang ramah lingkungan. Ramah lingkungan ini bisa didapatkan baik dari rancangan bangunannya ataupun penggunaan material yang digunakan dalam bangunan (Suminto, 2017). Salah satu bahan material daur ulang yang dapat digunakan untuk bangunan adalah ecobrick. Eco-brick ini adalah jenis bata yang ramah lingkungan terbuat dari sampah botol plastik kemasan yang diproses untuk menjadi bahan bangunan (Hijrah, 2010).

Terkait dengan pemanfaatan sampah botlol plastik menjadi eco brick kiranya menjadi hal yang menarik untuk disebar luaskan kepada masyarakat. Oleh karenanya dipandang perlu pemasyarakatan eco brick ini kepada seluruh lapisan masyarakat sedini mungkin. Untuk itu dilakukan upaya pengenalan dan pemanfaatan eco brick kepada masyarkaat khususnya para siswa Sekolah Dasar Kanisius Kembaran Yogyakarta. Tujuan semua ini adalah untuk mengurangi sampah plastik dan memampukan masyrakata mendaur ulang plastik menjadi sesuatu yang berguna.

Diharapkan melalui pengenalan dan pelatihan eco-brick ini siswa-siswa menjadi sadar akan lingkungan alamiah yang memburuk akibat sampah plastik dan mampu bertindak sesuai dengan kemampuannya untuk turut mengurangi sampah plastik. Demikian juga tentunya bagi seluruh stakeholder agar turut serta dalam pengurangan penggunaan plastik dan botol minum plastik karena membutuhkan waktu yang sangat lama untuk bisa terurai kembali (Darsono, 2005).

Pengenalan dan pelatihan eco brick kepada siswa-siswa SD Kanisius Kembaran sejatinya sejalan dengan visi dan misi Sekolah yang telah didirikan sejak tahun 1968 yang menekankan pada pendidikan dan pemberdayaan untuk membebaskan dari kebodohan. Kanisius sebagai yayasan dan sekolah berkomitmen pada upaya pemberdayaan bangsa melalui dunia pendidikan dan pemberdayaan masyarakat. Pada tahun 1926 mengembangkan wacana pendidikan melalui pencetakan bukubuku bacaan untuk memenuhi bahan pembelajaran sekolah-sekolah rakyat dengan tujuan membebaskan masyarakat dari kebodohan dan 
keterbelakangan. Kontekstualisasi yang diterjemahkan oleh sekolah ini pada saat ini adalah semangat untuk membebaskan masyarakat dari kebodohan dan keterbelakangan.

Saat ini pendidikan lebih diterjemahkan pada upaya menjawab tantangan global yang harus dilakukan secara nyata. Oleh karenanya menjadi tepat memilih siswa-siswa SD Kanisius Kembaran untuk diberikan pengenalan dan pelatihan eco-brick.

\section{METODE}

\subsection{Metode literasi}

Metode ini berupa penggalian secara literasi terkait dengan eco-brick. Penggalian ini dilakukan oleh tim pengabdian masyarakat prodi Arsitektur Universitas Widya Mataram melalui buku,litartur,artikel, dan juga web link seperti Introduction Ecobrick-A Sollution to Pullution dan How to Make Ecobrick, melalui metode ini diperoleh:

- pengetahuan mengenai sampah plastik, proses daur ulang dan imbas penumpukan sampah plastik terhadap lingkungan.

- $\quad$ proses pembuatan ecobrick,

- hasil akhir penggunaan ecobrik

\subsection{Metode survey}

Metode survey dilakukan untuk mencari sekolah yang dinilai tepat untuk dilakukan pengenalan dan pelatihan eco brick. Pengenalan akan pengolahan sampah sebaiknya dilakukan sedini mungkin, tim survey mencari komunitas yang menampung usia dini. Komunitas tersebut difokuskan pada sekolah di tataran dasar (usia < 12 tahun). Dari sekian banyak sekolah dasar yang tersebar di lingkungan Universitas Widya Mataram, tim survey memfokuskan ke sekolah yang sudah memiliki kegiatan terkait lingkungan hidup. Terpilihnya SD Kansisius Kembaran, dikarenakan sekolah tersebut sudah mengagendakan setiap hari Rabu dengan kegiatan Rabu Bersih serta sekolah tersebut, sangat terbuka dengan pelatihan-pelatihan sebagai penambah wawasan perserta didik.

Setelah itu, dilakukan survey lokasi sasaran kegiatan pengabdian masyarakat di SD Kanisius Kembaran. Dalam tahap oservasi lokasi ditentukan pula target atau siapa saja yang akan diberikan pelatihan Ecobrick. Dalam hal ini yang menjadi target pelatihan Ecobrick yaitu siswa-siswa SD Kanisius Kembaran yang duduk di kelas 4 dan kelas 5.

\subsection{Metode penyampaian materi}

Dengan melihat latar belakang usia target sasaran pelatihan Ecobrick yang masih berada pada fase anak-anak, maka tim pengabdian masyarakat menyusun metode penyampaian materi dengan cara yang menyenangkan supaya anak-anak mudah memahaminya. Penjelasan yang dilakukan yaitu dengan model penampilan video, menggunting dan menempel tema-tema yang terkait Ecobrick pada kertas dan praktek pembuatan Ecobrick. Satu minggu sebelum pelaksanaan pelatihan Ecobrick ini, tim pengabdian masyarakat menginformasikan kepada pihak sekolah SD Kanisisus Kembaran supaya menginformasikan kepada siswa-siswi nya untuk membawa botol air mineral bekas dan sampah-sampah plastik yang sudah dibersihkan.

Pelaksanaan kegiatan ini dilakukakan selama empat minggu. Minggu pertama dilakukan pengenalan tentang latar belakang mengapa harus membuat Ecobrick. Materi disampaiakn dengan metode video dan permainan menggunting dan menempel gambar. Minggu berikutnya mulai dilakukan pelatihan proses awal pembuatan Ecobrick dengan mencoba mengisi botol air mineral bekas dengan sampahsampah plastik yang sudah dikumpulkan. Dan pada dua minggu berikutnya dilakukan pendampingan untuk menyelesaikan project Ecobrick ini. 


\section{PELAKSANAAN KEGIATAN}

Kegiatan pengabdian kepada masyarakat ini dilakukan ditengahtengah isu mengenai meningkatnya limbah sampah plastik di bumi yang belum dapat terpecahkan masalahnya dengan baik. Sasaran atau target yang diberikan pelatihan ini adalah siswa siswa SD Kanisius Kembarangyang duduk di kelas 4 dan 5. Dipilih siswasiswi Sekolah Dasar bertujuan untuk menanamkan sejak dini mengenai kesadaran pengurangan penggunaan sampah plastik di kehidupan kita. Penanaman kesadaran sejak dini tersebut diharapkan dapat mampu mewujudkan generasi masa depan yang sadar akan kondisi bumi.

Pelatihan diawali dengan pengenalan sampah plastik dan bahayanya bagi tubuh manusia maupun lingkungan. Pengolahan sampah menggunakan metode ecobrick tergolong mudah, bahan yang diperlukan berupa sampah plastik. Sampah plastik dipilah menjadi dua, sampah halus seperti plastik 'kresek' dan sampah kasar seperti pembungkus makanan, plastik minyak goreng, mie instan, dan lain sebagainya. Agar dapat digunakan, sampah-sampah ini dibersihkan dari sisa-sisa bahan seperti makanan, minyak dan sabun kemudian keringkan. Selain kedua sampah tersebut, siapkan juga botol plastik bekas air mineral yang telah dibersihkan dan dikeringkan untuk media. Alat-alat yang diperlukan adalah gunting dan bambu ukuran $2 \times 40 \mathrm{~cm}$ untuk memadatkan sampah plastik di dalam botol.

Cara pengolahannya dimulai dari merobek sampah halus dengan warna yang sama, kemudian dimasukkan ke dalam botol dan padatkan menggunakan bambu hingga benar-benar padat, lapisan ini dijadikan sebagai lapisan dasar. Setelah sampah halus menjadi padat, lanjutkan dengan sampah kasar. Potong kecil sampah kasar menggunakan gunting, setelah itu masukan potongan tersebut kedalam botol dan padatkan kembali hingga botol penuh. Untuk membuat bangku kecil diperlukan minimal 7 botol dengan merk yang sama.

Dari kegiatan pelatihan ini dihasilkan dua buah modul Ecobrick yang dapat digunakan sebagai tempat duduk atau meja kecil para siswa di sekolah.

Melalui kegiatan ini siswa-siswi nampak antusias dalam kegiatan pelatihan pembuatan Ecobrick di SD Kanisius Kembaran. Mereka sangat menikmati kegiatan karena merasa kegiatan semacam ini menjadi semacam kegiatan untuk menyegarkan kembali pikiran mereka setelah setiap hari menempuh kegiatan belajar mengajar di sekolah.

Berikut ditunjukkan gambargambar proses pengenalan dan pelatihan pembuatan ecobrick :

\section{Pengenalan Ecobrick}

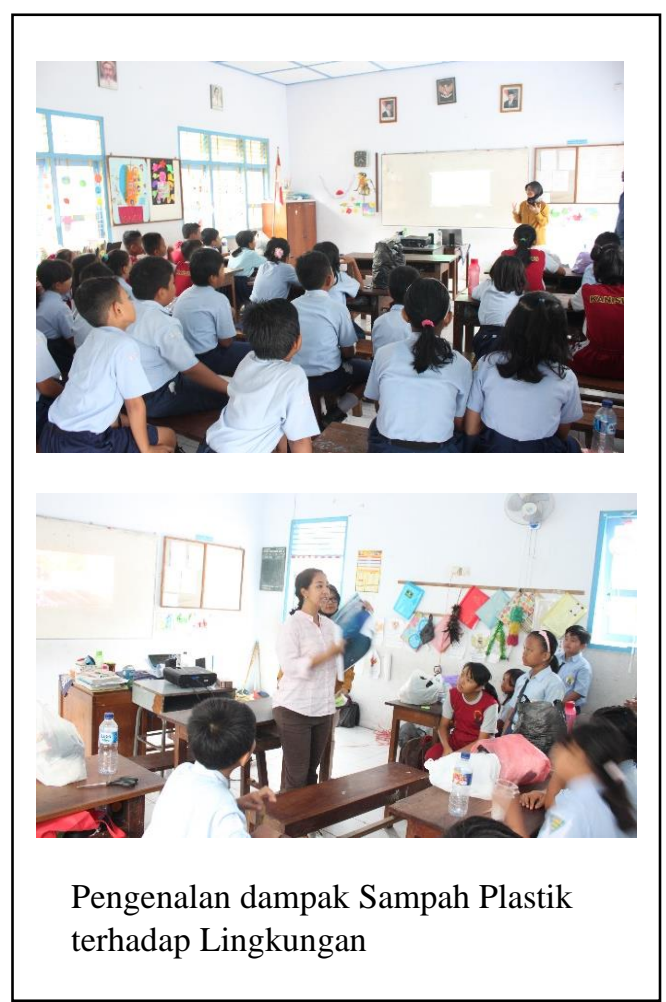

Gambar 1. Penjelasan Awal tentang Dampak Sampah

Sumber: Dokumentasi Penulis,2019 
lingkungan sekitar sekolah dan membersihkannya dari sisa-sisa makanan

Gambar 3. Tahap I. Pengumpulan sampah plastik

Sumber:Dokumentasi penulis,2019

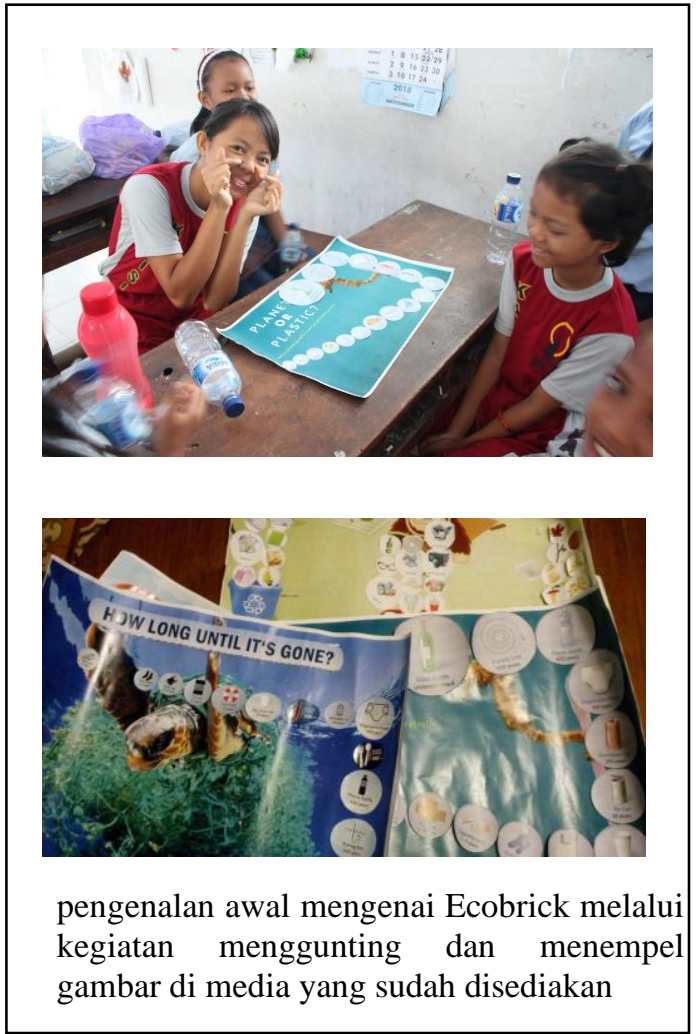

Gambar 2. Penjelasan mengenai Ecobrick Sumber:Dokumentasi Penulis, 2019

2. Pelatihan Pembuatan Ecobrick
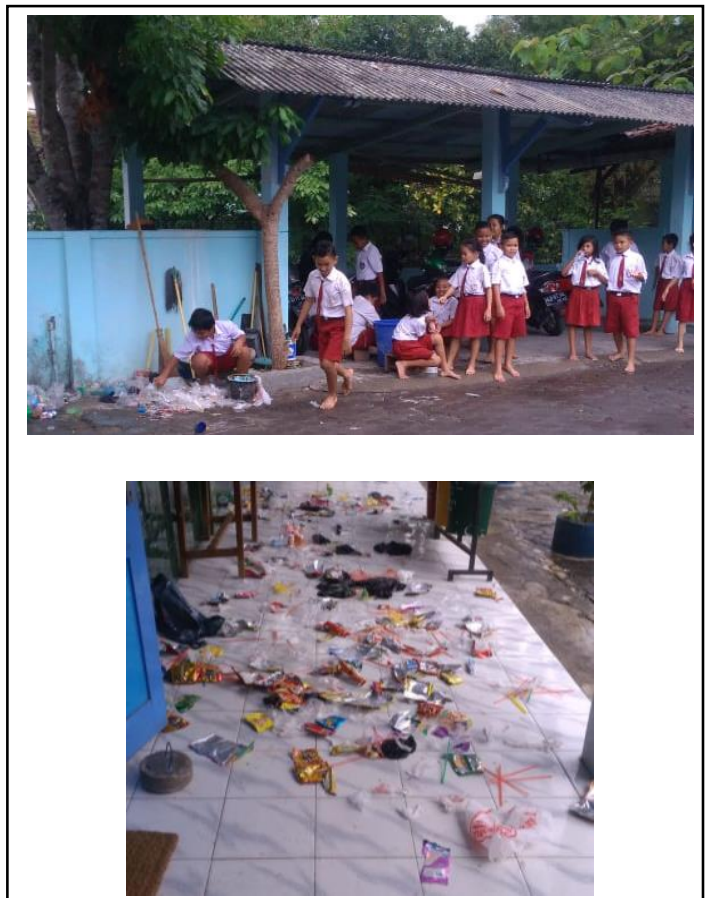

Persiapan siswa-siswi SD Kanisisus Kembaran mengumpulkan sampah-sampah plastik dari

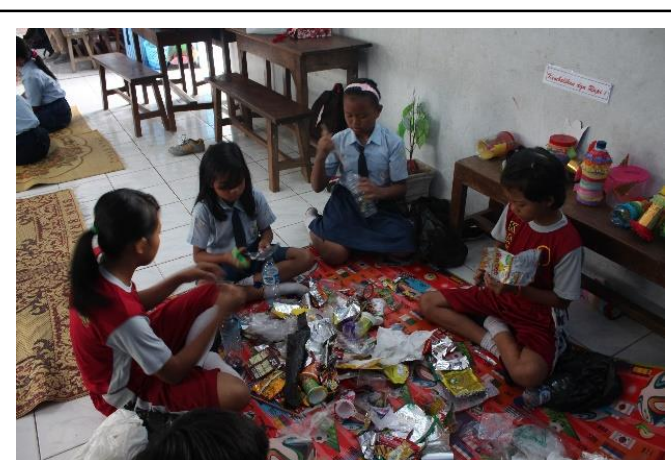

Pembuatan Ecobrick tahap awal memotong sampah plastik menjadi potongan kecil-kecil agar mudah di masukkan ke dalam botol

Gambar 4. Tahap II Pemotongan sampah plastik Sumber; Dokumentasi Penulis, 2019

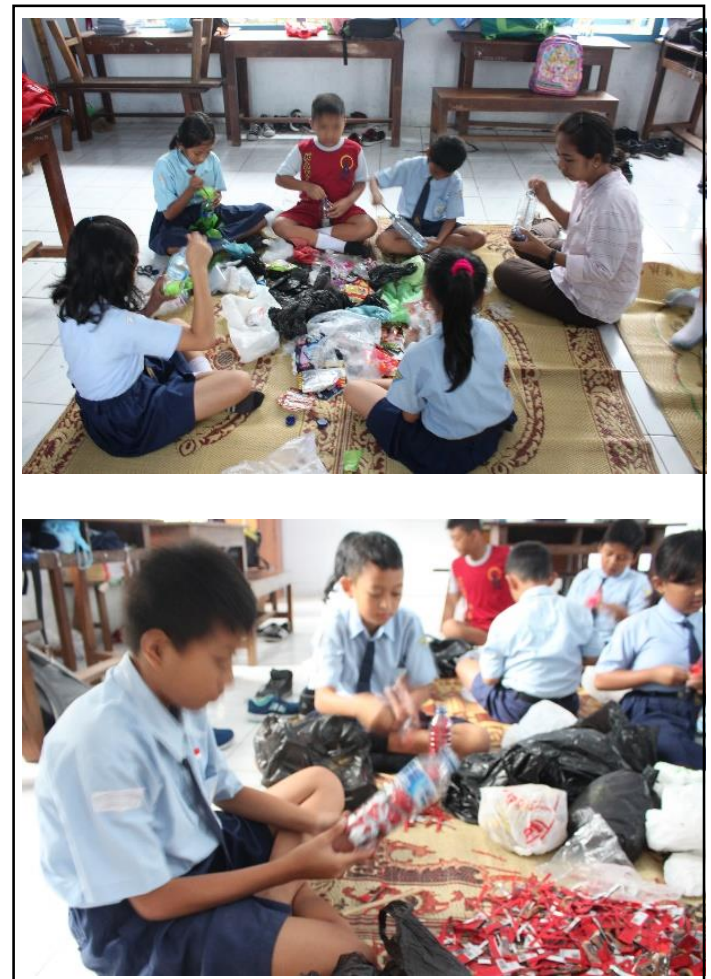

Tahap pengarahan pada pelatihan Ecobrick pada proses memasukkan sampah-sampah plastik ke dalam botol

Gambar 5. Tahap III Memasukkan sampah plastik kedalam botol

Sumber: Dokumentasi Penulsi, 2019 


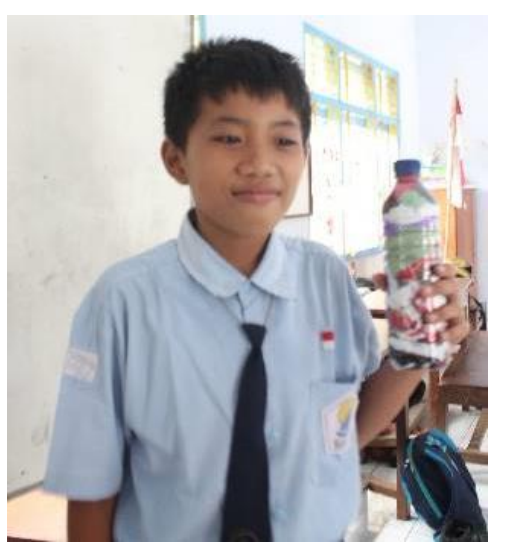

Salah satu siswa yang berhasil membuat satu unit botol dengan isian sampah plastic di pertemuan pertama

Gambar 6. Sampah plastik yang dimasukkan dalam botol

Sumber: Dokumentasi Penulis,2019

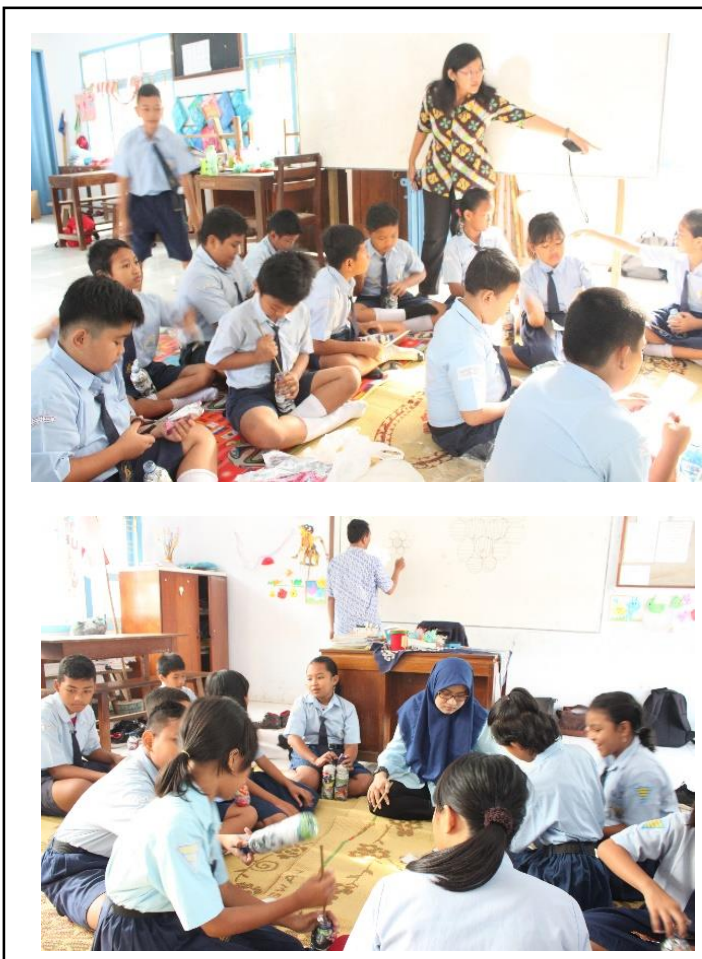

Beberapa pertemuan berikutnya mempunyai agenda memadatkan sampah plastik di dalam botol air mineral dan menghasilkan beberapa botol air mineral yang sudah dipadatkan.

Gambar 7. Tahap IV. Memastikan botol yang berisi sampah plastik cukup padat

Sumber: Dokumentasi Penulis, 2019

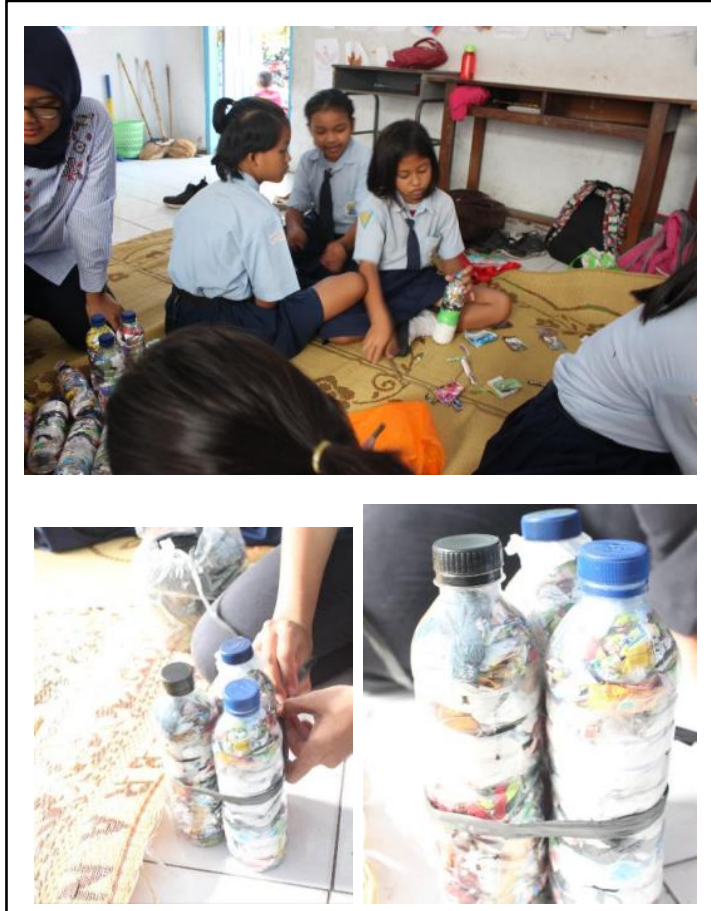

Pertemuan terakhir mulai menyusun modul Ecobrick dari botol-botol yang sudah diisi dengan sampah plastik dan dipadatkan.

Gambar 8. Tahap V Merangkai modul awal bangku

Sumber: Dokumentasi Penulis, 2019

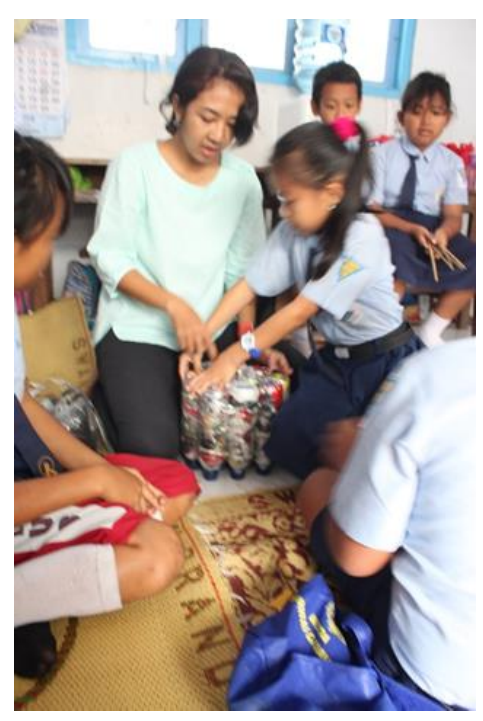

Proses pengikatannya yaitu menggunakan raffia dan direkatkan kembali menggunakan selotip 


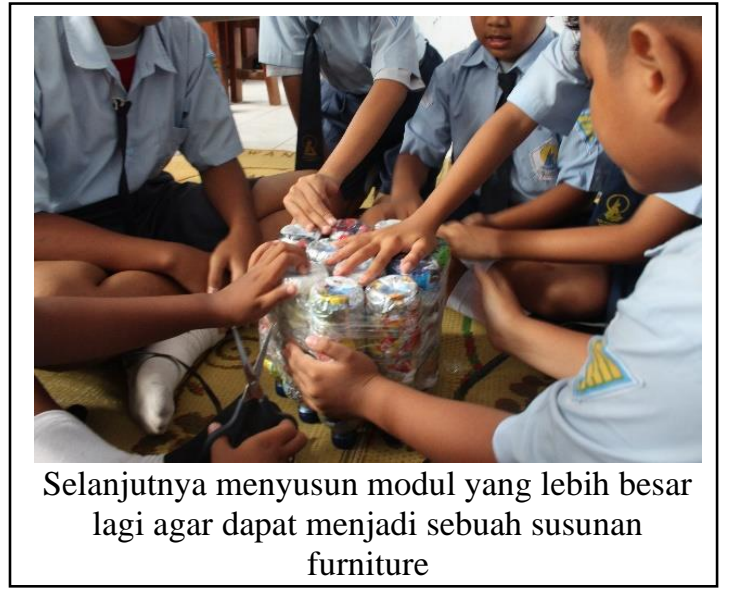

Gambar 9. Tahap VI. Perngakaian modul menjadi bangku

Sumber: Dokumentasi Penulis, 2019

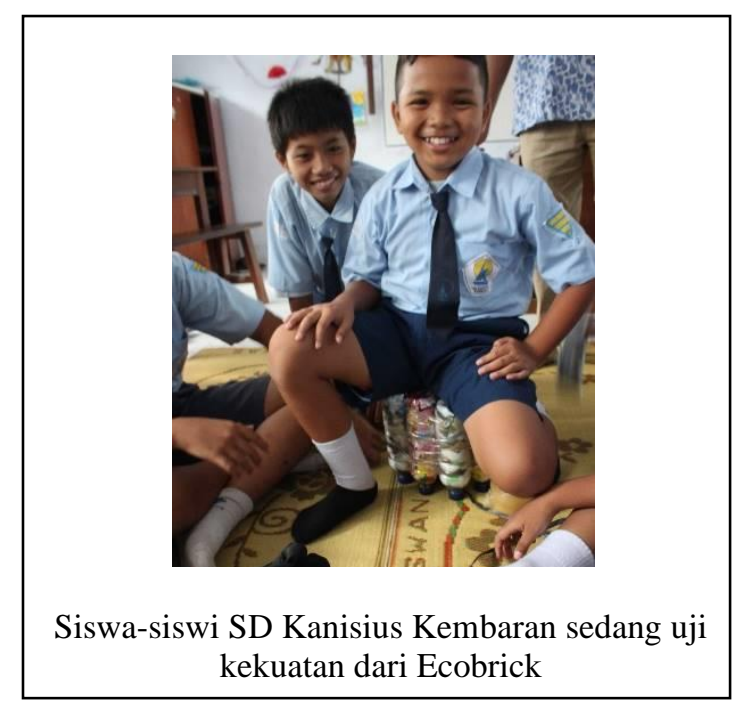

Gambar 10. Tahap VII. Uji kekuatan Sumber: Dokumentasi penulis,2019

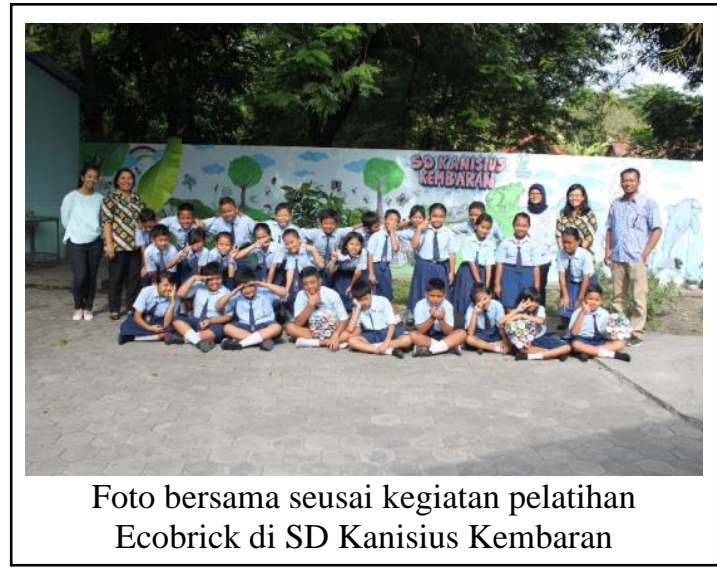

Gambar 14. Foto setelah kegiatan

Sumber;Dokumentasi Penulis, 2019

\section{PENUTUP}

Berdasarkan pelaksanaan kegiatan pengenalan dan pelatiahan ecobrick di SD Kanisius Kembaran dapat dikemukakan kesimpulan seperti di bawah ini.

1. Pelaksanaan pelatihan dapat berjalan dengan baik sesuai dengan proses dan metode yang diterapkan sehingga siswa-siswi SD Kanisius Kembaran nampak antusias dalam melaksanakan kegiatan pelatihan pembuatan Ecobrick. Mereka sangat menikmati kegiatan karena merasa kegiatan semacam ini menjadi semacam kegiatan untuk menyegarkan kembali pikiran mereka setelah setiap hari menempuh kegiatan belajar mengajar di sekolah

2. Siswa-siswi SD Kanisius Kembaran yang telah dilatih ecobrick berhasil dan mampu membuat ecobrick yang kemudian disusun menjadi sebuah bangku pendek atau dingklik

3. Pelatihan pembuatan ecobrick senyatanya telah turut serta mengurangi sampah plastikk dengan memanfaatkannya untuk dijadikan ecobrik.

\section{UCAPAN TERIMA KASIH}

Diucapkan terima kasih kepada LPPM Universitas Widya Mataram atas dana hibah Penelitian dosen belum berjabatan fungsional pendanaan tahun 2019, sehingga penelitian ini dapat berjalan dengan lancar.

\section{DAFTAR PUSTAKA}

Budi, Bambang Setia. Feb. 2006. Memisahkan Sampah:Belajar dari Jepang.

Darsono, V. 2005. Upaya Pengelolaan Sampah Perkotaan. Jurnal Teknologi Industri IX, 3 
Fatchurrahman, Taufik. (2018).

Manajemen Pengelolaan

Sampah Berkelanjutan Melalui

Inovasi "Ecobrick" oleh

Pemerintah Yogyakarta.

Universitas Muhammadiyah

Yogyakarta

Putra, Hijrah Purnama. (2010). Studi Pemanfaatan Sampah Plastik Menjadi Produk dan Jasa

Kreatif. Jurnal Sains dan

Teknologi Lingkungan Vol.2

Ramadhan, Hary. 1999. Sistem Daur

Ulang Limbah Plastik. Laporan

Kerja Praktek. Jurusan Teknik

Lingkungan Institut Teknologi

Sepuluh Nopember,Surabaya.

Sekartaji, Suminto. 2017. Solusi

Cerdas dan Kreatif untuk Mengatasi Sampah Plastik. Jurnal Desain Produk Vol.3 (Juli):247-252.

Wahyono, E.H. 2012. Pengelolaan

Sampah Plastik:Aneka

Kerajinan dari Sampah Plastik.

Yapeka, Bogor 